Work participation and physicality of work in young adulthood and the development of unhealthy lifestyle habits and obesity later in life : a prospective cohort study

\title{
Shiri, Rahman
}

2021-03

Shiri , R , Halonen , J , Serlachius , A , Hutri-Kähönen , N , Raitakari , O T, Vahtera , J , Viikari , J \& Lallukka , T 2021, ' Work participation and physicality of work in young adulthood and the development of unhealthy lifestyle habits and obesity later in life : a prospective cohort study ' , Occupational and Environmental Medicine , vol. 78 , no. 3 , pp. 153-159 . https://doi.org/10.1136/oemed-2020-106526

http://hdl.handle.net/10138/337603

https://doi.org/10.1136/oemed-2020-106526

cc_by_nc

acceptedVersion

Downloaded from Helda, University of Helsinki institutional repository.

This is an electronic reprint of the original article.

This reprint may differ from the original in pagination and typographic detail.

Please cite the original version. 


\section{Work participation and physicality of work in young adulthood and the development of obesity and unhealthy lifestyle habits later in life: A}

prospective cohort study

Rahman Shiri ${ }^{1}$, Jaana I. Halonen ${ }^{2}$, Anna Serlachius ${ }^{3}$, Nina Hutri-Kähönen ${ }^{4}$, Olli Raitakari ${ }^{5,6,7}$, Jussi Vahtera ${ }^{6,8}$, Jorma Viikari ${ }^{9}$, Tea Lallukka ${ }^{1,10}$

${ }^{1}$ Finnish Institute of Occupational Health, Helsinki, Finland

${ }^{2}$ Finnish Institute for Health and Welfare, Helsinki, Finland

${ }^{3}$ Department of Psychological Medicine, Faculty of Medical and Health Sciences, University of Auckland, Auckland, New Zealand

${ }^{4}$ Department of Paediatrics, Faculty of Medicine and Health Technology, Tampere University and Tampere University Hospital, Tampere, Finland

${ }^{5}$ Research Centre of Applied and Preventive Cardiovascular Medicine, University of Turku, Turku, Finland

${ }^{6}$ Centre for Population Health Research, University of Turku and Turku University Hospital, Turku, Finland

${ }^{7}$ Department of Clinical Physiology and Nuclear Medicine, Turku University Hospital, Turku, Finland

${ }^{8}$ Department of Public Health, University of Turku, Turku, Finland

${ }^{9}$ Department of Medicine, University of Turku, Turku, Finland; Division of Medicine, Turku University Hospital, Turku, Finland.

${ }^{10}$ Department of Public Health, University of Helsinki, Helsinki, Finland

Running head: Work participation and risky lifestyle habits 
Abstract word count: 249

Text word count: 3,500

Number of tables: 3

Number of figures: 0

Number of supplemental tables: 8

Number of supplemental figures: 1

\section{Correspondence to:}

Rahman Shiri

Finnish Institute of Occupational Health

P.O. Box 18

FI-00032 Työterveyslaitos, Helsinki

Email: rahman.shiri@ttl.fi

\section{Funding source}

The Academy of Finland (Grants \#287488 and \#319200) supported this study.

\section{Conflict of interest}

The authors declare that they have no conflicts of interest.

\section{Authors' contributions}

RS, JIH, AS, NH-K, OR, JV, JV and TL meet the criteria of authorship and planned the study. RS analysed the data and drafted the manuscript. All authors contributed to the interpretation of the results and critical revision of the manuscript and approved the final version of the manuscript for publication. 


\section{What is already known about this subject?}

- The effects of work-related factors in young adulthood and early entry into employment on the development of adverse health behaviours later in life are unclear.

\section{What are the new findings?}

- Physicality of work in young adulthood increased the rate of future obesity and smoking, particularly among women.

- The rates of smoking and obesity were higher, and the rate of leisure-time physical activity was lower in people who entered the labour market at ages $18-21$ or younger compared to those who entered the labour market at ages 22-24.

\section{How might this impact on policy or clinical practice in the foreseeable future?}

- The roots of unhealthy behaviours and obesity begin in young adulthood. Thus, preventive measures or interventions that start in midlife could be too late to be effective. Prevention of obesity and unhealthy behaviours should start in adolescence and young adulthood, paying special attention to young people in physically heavy jobs and those who enter the labour market early. 


\begin{abstract}
Objective: To determine the effects of early entry into the labour market and physicality of work in young adulthood on the development of obesity and unhealthy lifestyle habits later in life.

Methods: This study is a part of the Young Finns Study. Entry into the labour market and physicality of work were measured at baseline, when participants were aged 18, 21, or 24 years in 1986, or 18 years in 1989. Follow-up of lifestyle habits were conducted in 2001, 2007 and 2011. The outcomes were obesity ( $\mathrm{N}=5558$ observations), abdominal obesity ( $\mathrm{N}=4060$ observations), daily smoking $(\mathrm{N}=5628)$ and leisure-time physical activity $(\mathrm{N}=5946)$ and analysed with generalized estimating equation.
\end{abstract}

Results: Compared with sedentary work, physicality of work in young adulthood increased the odds of future obesity (adjusted odds ratio $(\mathrm{OR})=1.32,95 \%$ CI 1.01-1.74 for light/moderate work and $\mathrm{OR}=1.44$, CI 0.99-2.08 for heavy manual work [particularly in women $\mathrm{OR}=2.03$, CI 1.07-3.84]) and future smoking $(\mathrm{OR}=1.79, \mathrm{CI} 1.39-2.30$ for light/moderate work and $\mathrm{OR}=2.01$, CI 1.47-2.76 for heavy manual work [particularly in women OR=2.81, CI 1.60-4.91]). For those who entered the labour market at ages 18-21 or younger, the odds of smoking was 1.85 times (CI 1.26-2.73) and that of obesity 1.45 times (CI 1.01-2.10) higher, and the rate of leisure-time physical activity was 0.73 times (CI 0.58-0.93) lower compared with those who entered the labour market at ages 22-24.

Conclusion: Early entry into the labour market and physicality of work in young adulthood shape the development of obesity and unhealthy behaviours in later adulthood.

Keywords: Exercise; overweight; weight gain; work engagement; workload; smoking 


\section{Introduction}

Unhealthy lifestyle habits such as smoking, lack of physical activity, and also excess body mass are among the leading contributors to deaths and disability-adjusted life-years worldwide. ${ }^{1}$ The role of work-related factors in the development of adverse health behaviours is unclear. Previous research has primarily focused on midlife and older adults, with few studies exploring whether entry into paid employment and adverse work exposure in early adulthood shape the development of unhealthy lifestyle habits and obesity in later life.

Associations between adverse working conditions and body mass index (BMI) remain unclear. A study conducted in Australian adults reported that inflexible working hours and working on weekends predicted weight gain. ${ }^{2}$ Sex difference has also been observed between adverse working conditions and weight gain. For example, in a Finnish prospective cohort study, unfavourable physical working conditions increased the risk of weight gain in men, but not in women. ${ }^{3}$ On the other hand, in a Swedish cohort, high job demands increased the risk of weight gain in women, but not in men. ${ }^{4}$ Studies have also observed that physical demands, ${ }^{5}$ psychological demands ${ }^{25}$ and job type ${ }^{2}$ do not increase the risk of obesity. A review of 22 crosssectional and prospective studies found inconclusive results on the association between work stress (effort/reward imbalance and job strain) and body weight. ${ }^{6}$ Furthermore, a meta-analysis of prospective cohort studies reported that job strain does not increase the risk of weight gain or obesity. ${ }^{7}$

Early entry into employment can be stressful for some young adults. As a consequence of high stress, young adults may adopt unhealthy behaviours, for example, they may start to smoke as a coping mechanism. ${ }^{8}$ First jobs could also be lower-paid occupations and workers may have poor access to healthy foods in the workplace. Moreover, co-workers' behaviours may influence 
young workers' lifestyle habits. ${ }^{9}$ Previous prospective cohort studies on smoking reported that early transition from education to employment in young adults ${ }^{8}$ and working long hours in adults ${ }^{10} 11$ increased the risk of smoking. Working long hours not only increased the number of cigarettes smoked daily, but also increased the rate of smoking among former smokers and reduced the rate of quitting smoking among current smokers. ${ }^{11}$ However, working longer hours predicted lower risk of smoking among middle aged Finnish and Japanese men. ${ }^{12}$ On the other hand, high physical exertion and high psychological demands predicted heavy smoking among adults. ${ }^{13}$

Regarding leisure-time physical activity (LTPA), a study ${ }^{14}$ reported that middle-aged employees with physically demanding jobs may reduce their LTPA, while sedentary workers may increase their LTPA. Another study ${ }^{15}$ found that working long hours is associated with a lower rate of LTPA. However, prospective cohort studies have reported inconsistent results; some reported that working long hours is not significantly associated with LTPA among working age adults, ${ }^{10}$ 1216 while others reported reduced LTPA in those who worked longer hours. ${ }^{17}{ }^{18}$ A lower grade job (lower supervisory and technical) has also been associated with reduced LTPA among adults aged 16 or older. ${ }^{17}$

As demonstrated above, the adverse effects of early entry into employment and physicality of work in early adulthood on the risk of excess body mass and unhealthy lifestyle habits later in life are unclear. Longitudinal studies examining the association between adverse working conditions in young adulthood and health behaviours and BMI in later adulthood are scarce. If the roots of unhealthy behaviours and obesity in midlife begin in one's early career, preventive measures in midlife would be too late. Furthermore, unhealthy behaviours and obesity predict work disability and premature exit from paid employment. ${ }^{19}{ }^{20}$ It is thus important to identify modifiable determinants, such as adverse early career work exposures. 
In the current study, we aimed to determine whether early entry into first employment and physicality of work in young adulthood shape the development of unhealthy lifestyle habits in adulthood. In addition, we aimed to identify sensitive periods in young adulthood when entry into labour market is most harmful regarding the development of obesity and adverse health behaviours. 


\section{Methods}

\section{Population}

This study is a part of the Young Finns Study. Of 4,320 children and adolescents aged 3-18 years, 3,596 (83\%) participated in the baseline assessment in 1980 (Figure S1). ${ }^{21}$ The participants were invited from five Finnish university cities. The follow-ups were conducted in 1983, 1986, 1989 (subpopulation, N=632), 1992 (subpopulation, N=891), 2001, 2007 and 2011. The local ethics committees approved the study protocol and the participants gave written informed consent. Work exposures were not relevant for most of the initial baseline participants, and physicality of work was introduced in the later surveys. We therefore considered 1986 and 1989 follow-ups as the baseline of the current study, and included participants aged 18, 21, or 24 in 1986, and those who turned 18 in 1989. Subsequent surveys (2001, 2007 and 2011) were used for the follow-up of the unhealthy lifestyle habits when the participants were aged 30-49 years. There were 5558 observations with data on obesity, 4060 with data on abdominal obesity, 5628 with data on smoking and 5946 observations with data on LTPA.

\section{Independent variables}

Information on physicality of work, entry into first employment and age at entry into paid employment was based on data collected in 1986/1989. The question on physicality of work had six alternative responses: 1) 'lightweight sitting', 2) 'other sedentary work', 3) 'physically light standing or light mobile work', 4) 'physically light to moderate mobile work', 5) 'heavy manual labour', and 6) 'very heavy manual labour'. ${ }^{22} 23$ We classified physicality of work into three groups: 1) sedentary work (1 and 2), 2) light standing or light/moderate mobile work (3 and 4), and 3) heavy manual work (5 and 6). Information on entry into first employment was inquired as a yes/no question as well as the year of employment between 1978 and 1989. For participants 
who entered the labour market, we classified the age when entering first employment at baseline into: 1) 18 years or younger, 2) 19-21 years, 3) 22-24 years, and 4) 25-27 years.

\section{Outcomes}

Obesity. Body weight and height were measured at baseline and three follow-up study waves and obesity was defined as a BMI $\geq 30 \mathrm{~kg} / \mathrm{m}^{2} .{ }^{24}$ Waist circumference was measured in 2001, 2007 and 2011 (N=4060 observations) and abdominal obesity was defined as waist circumference $\geq 102 \mathrm{~cm}$ for men and $\geq 88 \mathrm{~cm}$ for women. ${ }^{24} 25$

Smoking. We used a self-administered questionnaire to collect data on smoking at all time points. Smoking status was classified into four groups: 1) never smoked; 2) former smokers; 3) occasional smokers; and 4) daily smokers. We used daily smoking as an outcome.

Leisure-time physical activity. LTPA was assessed by the same questionnaire at all time points. The questions and construction of the LTPA index have been published in an earlier report. ${ }^{26}$ The five questions assessed: 1) intensity of LTPA, 2) frequency of vigorous LTPA, 3) number of hours spent in vigorous LTPA, 4) average duration of a LTPA session, and 5) participation in organized LTPA. ${ }^{26}$ The participant's responses to the five questions were summed to calculate a LTPA index for each time point. The LTPA index ranged between 5 and 15 . We used a cut-off point of 11 or higher to define moderate or vigorous LTPA at least twice a week. ${ }^{26}$

\section{Other covariates}

A self-administered questionnaire was used to collect information on age, gender, and parental and participant's socioeconomic status. Parental occupation and education, and household income were assessed in $1980 .{ }^{27}$ Parental occupation was assessed in five classes: 1) upper nonmanual, 2) lower non-manual, 3) upper manual, 4) lower manual, and 5) farmers. Parental 
education was classified into three levels based on years of education of the more educated parent: 1) <9 years, 2) 9-12 years, and 3) >12 years. The household income was classified into three levels: 1) below average (lowest quartile), 2) mean (two middle quartiles), and 3) above average (highest quartile). Participant's educational status (comprehensive school; secondary education, not academic; and academic) and occupational status (manual; lower-grade nonmanual; and higher-grade non-manual) were assessed in 2001, when they were aged 30-39 years.

\section{Statistical analysis}

Missing data at baseline ranged between $0.9 \%$ and $3.4 \%$ for parental education and occupation, household income, BMI, smoking and physical activity. It was $17.1 \%$ for participants' education and $26.2 \%$ for participants' occupational class. We used multiple imputation to impute the missing data on the covariates and created 10 datasets. We included age, sex, educational level, occupational status, parental education and occupation, income, physicality of work, entry into first employment, and lifestyle habits (in all time points) in the imputation models. A generalized estimating equation ${ }^{28}$ was used to analyse the associations of physicality of work, entry into first employment and age at entry into employment with unhealthy lifestyle habits using repeated measures data on lifestyle habits. For age at entry into the labour market, those who entered the labour market at ages 22-24 years served as the reference group, because this age group includes typical age to finish education (by 23 years) and was considered to enter employment neither too early nor late, and a majority had already entered into employment. The estimates were adjusted for age, gender, parents' education and occupation, household income, participant's educational level and occupational status at age 30 years or older, physicality of work, entry into first employment, smoking (a 4-group variable), BMI (continuous variable), and LTPA (continuous variable). Gender-specific analyses were performed to determine whether the adverse effects of early entry into the labour market on 
lifestyle habits differ by gender. Furthermore, as sensitivity analyses, the participants with the unhealthy outcome of interest prevalent already in 1986/1989 (overweight/obesity [BMI $\geq 25$ $\mathrm{kg} / \mathrm{m}^{2}$ ], smoking), or participates who turned 18 in 1989 were excluded from the analyses. Stata, version 15, (StataCorp, College Station, TX, USA) was used for the analyses. 


\section{Results}

Of the study population, $58 \%$ had entered the labour market for the first time at ages $15-27$ years in 1978-1989 and 15.5\% had heavy manual work at baseline in 1986/1989 (Table 1). At baseline, $13 \%$ were overweight or obese, $24 \%$ were daily smokers and $21 \%$ were physically active during leisure-time. In 2001, $17 \%$ were abdominally obese.

\section{Obesity}

After controlling for confounders, the odds of obesity during the follow-up was higher among participants whose work in young adulthood had required light standing or light/moderate mobile work (adjusted odds ratio $(\mathrm{OR})=1.32,95 \%$ CI 1.01-1.74) and among those with heavy manual work (OR=1.44, CI 0.99-2.08) compared with sedentary workers (Table 2). In genderspecific analyses, the association reached statistical significance after adjustment for confounders in women only (OR=2.03, CI 1.07-3.84 for heavy manual work, Table S1). The odds of obesity did not differ between participants who entered the labour market at baseline and those who entered later. In age-specific analysis, the prevalence of obesity was $2.2 \%$ in $1996 / 1998,18.0 \%$ in $2001,22.6 \%$ in 2007 and $28.6 \%$ in 2011 in participants who entered the labour market at age 18 years or younger. The corresponding estimates were $0.9 \%, 11.3 \%$, $14.5 \%$ and $17.3 \%$ respectively in those who did not enter the labour market at age 18 . After adjustment for covariates, the odds of obesity was higher in participants who entered the labour market at ages $18-21$ or younger $(\mathrm{OR}=1.45$, CI $1.01-2.10)$, especially at age 18 or younger $(\mathrm{OR}=1.60, \mathrm{CI} 1.06-2.41$, Table 3$)$, than in those who entered the labour market at ages 22-24. In contrast, in older participants, the odds of obesity was higher among those aged 27 who did not enter the labour market in 1978-1989 (OR=2.13, CI 1.12-4.06, Table 3) compared with participants who entered the labour market at ages 22-24. Excluding participants with overweight/obesity ( $\mathrm{N}=191$ observations) in 1986-89 did not change the magnitude of the 
associations, however, the estimate for heavy manual work (OR=1.50, CI 1.04-2.18) became stronger. In age- and gender-specific analyses (Table S2), the odds of obesity was higher in women who entered the labour market at age 18 or younger compared with women who entered the labour market at ages $22-24(\mathrm{OR}=1.90, \mathrm{CI} 1.13-3.20)$. In a sensitivity analysis, we explored the cohort effect and excluded participates who turned 18 in 1989. The OR of obesity increased from 1.60 (CI 1.06-2.41) to 1.79 (CI 1.14-2.80) for participants who entered the labour market at age 18 or younger.

\section{Abdominal obesity}

After adjustment for confounders, participants with light standing or light/moderate mobile work $(\mathrm{OR}=1.30, \mathrm{CI} 1.04-1.63)$ and those with heavy manual work $(\mathrm{OR}=1.48, \mathrm{CI} 1.10-1.99)$ were at a higher odds of abdominal obesity during the follow-up compared with sedentary workers (Table S3). Participants who entered the labour market during 1978-1989 were not at higher odds of abdominal obesity compared with those who entered the labour market later. In the age-specific analysis, the odds of abdominal obesity was higher in participants who entered the labour market at age 18 or younger compared with those who entered it at ages 22-24 $(\mathrm{OR}=1.43$, CI 1.01-2.01, Table S4). However, after further adjustment for participants' education and occupational class, and physicality of work (for entry into first employment), and entry into first employment (for physicality of work), none of the estimates remained statistically significant. The associations did not differ between men and women.

\section{Smoking}

Physicality of work was associated with increased odds of smoking (Table 2). After adjustment for confounders, the odds of regular smoking increased in participants with light standing or light/moderate mobile work (adjusted $\mathrm{OR}=1.79$, CI 1.39-2.30) and in participants with heavy 
manual work $(\mathrm{OR}=2.01$, CI 1.47-2.76) compared with sedentary workers (Table 2). This increase in smoking rate was observed in both men and women (Table S5).

Entering first employment at baseline was not associated with smoking (Table 2) and this finding was similar among men and women (Table S5). In age-specific analysis, the prevalence of daily smoking was $30.5 \%$ in 2007 and $26.9 \%$ in 2011 in participants who entered the labour market at age 18 years or younger. The corresponding estimates were $12.1 \%$ and $11.1 \%$ respectively in those who did not enter the labour market at age 18. After adjustment for confounders, the odds of smoking was higher in participants who entered the labour market at ages $18-21$ or younger $(\mathrm{OR}=1.85, \mathrm{CI} 1.26-2.73)$, particularly at age 18 or younger $(\mathrm{OR}=2.36, \mathrm{CI}$ 1.55-3.58, Table 3), than in those who entered the labour market at ages 22-24. Excluding daily smokers in 1986-89 (N=347 observations) from the analyses did not change the findings. Both men $(\mathrm{OR}=2.36$, CI 1.25-4.45) and women $(\mathrm{OR}=2.33$, CI 1.32-4.10) who entered the labour market at age 18 or younger had higher odds of smoking (Table S6). On the other hand, in older participants, the odds of smoking was again higher among those aged 27 who did not enter the labour market at baseline (OR=2.08, CI 1.11-3.92, Table 3) compared with participants who entered the labour market at ages 22-24. In the sex-specific analysis, this estimate was statistically significant in women only $(\mathrm{OR}=2.78$, CI 1.09-7.08, Table S6). After excluding participates who turned 18 in 1989 , the OR of smoking increased from 2.36 (CI 1.55-3.58) to 2.74 (CI 1.78-4.22) for participants who entered the labour market at age 18 years or younger.

\section{Leisure-time physical activity}

Physicality of work at baseline was not associated with the rate of LTPA during the follow-up (Table 2 and Table S7). However, there was a tendency of being less physically active during leisure-time in participants who entered the labour market at baseline than in those who entered later (Table 2). In age-specific analysis, participants who entered the labour market at ages 18- 
21 or younger were less physically active in leisure time $(\mathrm{OR}=0.73$, CI $0.58-0.93)$ than participants who entered the labour market at ages $22-24$. The OR was 0.72 (95\% CI 0.54.0.96, Table 3) for participants who entered the labour market at age 18 or younger and 0.74 (CI 0.58 0.95, Table 3) for those who entered the labour market at ages 19-21. In age- and genderspecific analyses, the estimates did not reach statistical significance (Table S8). For participants entering the labour market at age 18 years or younger, the OR of LTPA did not change after excluding participates who turned 18 in 1989 (OR=0.71, CI 0.52-0.96). 


\section{Discussion}

Physicality of work in early adulthood increased the rate of obesity and regular smoking in adulthood even after adjustment for own and parental socioeconomic measures. Entry into the labour market at younger ages increased the rate of obesity and smoking and reduced the rate of LTPA in adulthood.

Of working conditions, working long hours has been well studied in relation to obesity or weight gain. Working long hours has been associated with unhealthy weight gain among adults aged 18-64 years, ${ }^{10}$ 29-32 including increased $\mathrm{BMI}^{29} 3132$ and waist circumference ${ }^{29}$. In contrast, other prospective cohort studies have not observed an association between working hours and the risk of obesity. ${ }^{251218}$ To date, only a limited number of prospective cohort studies have determined the effects of physicality of work on the risk of overweight or obesity, and have reported inconsistent associations. ${ }^{23532}$ Previous studies have reported that workload, ${ }^{3}$ job type ${ }^{2}$ increased physical strain at work ${ }^{32}$ and physical demands ${ }^{5}$ are not associated with the risk of obesity or weight gain. In addition, another study reported that people exposed to light or moderate work-related physical activity were at a higher risk of weight gain than those exposed

to heavy work-related physical activity. ${ }^{33}$ In the present study, we found that physicality of work in early adulthood and early entry into first employment increased the risk of obesity, particularly among women. Furthermore, the study adds new knowledge that people aged 27 years who are still without first employment are at higher risk of obesity compared with those who entered the labour market earlier. Physicality of work is more likely linked to low education and low-level jobs, with poor access to healthy food and/or more prevalent unhealthy behaviours. Having lunch at a workplace canteen has been associated with healthier food habits,${ }^{34}$ and low education has been linked to lower access to workplace canteen. ${ }^{34}$ Young 
people are more likely to get hired for low level jobs at workplaces having poor access to healthy foods. Young people also often have lower level of education that has been linked to poor health behaviours. ${ }^{35}$ Eating habits of young workers are also influenced by their older coworkers. ${ }^{936}$

In the present study, we observed that physicality of work and early entry into first employment increased the rate of smoking. There is prior evidence that the work environment may influence smoking behaviour. ${ }^{37}$ High job demands such as high workload, psychological job demands, and working long hours were also reported to increase the number of cigarettes smoked among smokers and the probability of relapse after quitting smoking among former smokers. ${ }^{37}$ Furthermore, exposure to high physical workload ${ }^{38}$ and job stress ${ }^{39}$ may reduce the rate of smoking cessation. However, unemployment may also increase the risk of smoking in young adults from low socioeconomic backgrounds. ${ }^{40}$ On the other hand, unemployed young adults may decrease their cigarette use because of income loss. ${ }^{40}$ The present study adds additional knowledge that people aged 27 years without first employment are at an increased risk of daily smoking than those who entered the labour market earlier.

The associations of exposure to workload factors in young adulthood and early work participation with the rate of LTPA are not known. Previous studies reported that lower supervisory and technical jobs are associated with lower rates of LTPA in working age adults compared with a higher managerial or professional job. ${ }^{17}$ The present study therefore adds to the literature by suggesting that entry into the labour market at ages 18-21 years or younger is associated with a lower rate of LTPA in later adulthood. 


\section{Strengths and limitations}

Strengths of the study include its prospective nature and that weight, height, and LTPA were measured from childhood to adulthood. However, the study had also some limitations. Information on physicality of work was collected using only a single question and the study lacked data on different types of physical workload factors. Moreover, information on physicality of work was not collected at the 2001 follow-up study and no data on waist circumference were collected before the 2001 survey. We imputed missing data on covariates, but not missing data on physical workload factors and the outcomes. The proportion of the participants who were lost to follow-up or had missing data on the outcomes of the interest at follow-ups ranged between $22 \%$ and $40 \%$. A small proportion of the participants had missing data on the lifestyle habits and the main reason of sample attrition was loss to follow-ups. The rate of loss to follow-up or missing data on BMI and lifestyle habits did not differ between the participants with or without work participation and between the participants with different levels of physicality at baseline. Only the rate of loss to follow-up or missing data on LTPA at the 2011 follow-up was significantly higher among the participants with heavy manual work compared with those with sedentary or light/moderate mobile work.

\section{Conclusion}

Physicality of work in young adulthood and early entry into the labour market increased the rate of obesity and unhealthy behaviours in later adulthood. Prevention of unhealthy behaviours should start in adolescence and young adulthood, paying special attention to young people in physically heavy jobs and those who enter the labour market early. 


\section{References}

1 GBD 2017 Risk Factor Collaborators. Global, regional, and national comparative risk assessment of 84 behavioural, environmental and occupational, and metabolic risks or clusters of risks for 195 countries and territories, 1990-2017: a systematic analysis for the Global Burden of Disease Study 2017. Lancet 2018;392:1923-1994.

2 Magee CA, Caputi P, Stefanic N, Iverson DC. Occupational factors associated with 4year weight gain in Australian adults. J Occup Environ Med 2010;52:977-81.

3 Roos E, Lallukka T, Rahkonen O, Lahelma E, Laaksonen M. Working conditions and major weight gain-a prospective cohort study. Arch Environ Occup Health 2013;68:16672.

4 Klingberg S, Mehlig K, Johansson I, Lindahl B, Winkvist A, Lissner L. Occupational stress is associated with major long-term weight gain in a Swedish population-based cohort. Int Arch Occup Environ Health 2019;92:569-576.

5 Marchand A, Beauregard N, Blanc ME. Work and non-work stressors, psychological distress and obesity: evidence from a 14-year study on Canadian workers. BMJ Open 2015;5:e006285.

6 Siegrist J, Rodel A. Work stress and health risk behavior. Scand J Work Environ Health 2006;32:473-81.

7 Kivimäki M, Singh-Manoux A, Nyberg S, Jokela M, Virtanen M. Job strain and risk of obesity: systematic review and meta-analysis of cohort studies. Int J Obes (Lond) 2015;39:1597-600.

8 Green MJ, Leyland AH, Sweeting H, Benzeval M. Causal effects of transitions to adult roles on early adult smoking and drinking: Evidence from three cohorts. Soc Sci Med 2017; 187:193-202. 
9 Quist HG, Christensen U, Carneiro IG, Hansen JV, Bjorner JB. Do colleagues influence our lifestyle: the matter of smoking, body mass index and leisure-time physical activity? Prev Med 2014;67:166-70.

10 Shields M. Long working hours and health. Health Rep 1999;11:33-48(Eng); 37-55(Fre).

11 Angrave D, Charlwood A, Wooden M. Working time and cigarette smoking: evidence from Australia and the United Kingdom. Soc Sci Med 2014;112:72-9.

12 Lallukka T, Lahelma E, Rahkonen O, et al. Associations of job strain and working overtime with adverse health behaviors and obesity: evidence from the Whitehall II Study, Helsinki Health Study, and the Japanese Civil Servants Study. Soc Sci Med 2008;66:1681-98.

13 Dobson KG, Gilbert-Ouimet M, Mustard CA, Smith PM. Association between dimensions of the psychosocial and physical work environment and latent smoking trajectories: a 16-year cohort study of the Canadian workforce. Occup Environ Med 2018;75:814-821.

14 Nooijen CFJ, Del Pozo-Cruz B, Nyberg G, Sanders T, Galanti MR, Forsell Y. Are changes in occupational physical activity level compensated by changes in exercise behavior? Eur J Public Health 2018;28(5):940-943.

15 Kirk MA, Rhodes RE. Occupation correlates of adults' participation in leisure-time physical activity: a systematic review. Am J Prev Med 2011;40:476-85.

16 Angrave D, Charlwood A, Wooden M. Long working hours and physical activity. $J$ Epidemiol Community Health 2015;69:738-44.

17 Popham F, Mitchell R. Leisure time exercise and personal circumstances in the working age population: longitudinal analysis of the British household panel survey. J Epidemiol Community Health 2006;60:270-4. 
18 Taris TW, Ybema JF, Beckers DG, Verheijden MW, Geurts SA, Kompier MA. Investigating the associations among overtime work, health behaviors, and health: a longitudinal study among full-time employees. Int J Behav Med 2011;18:352-60.

19 Robroek SJ, Reeuwijk KG, Hillier FC, Bambra CL, van Rijn RM, Burdorf A. The contribution of overweight, obesity, and lack of physical activity to exit from paid employment: a meta-analysis. Scand J Work Environ Health 2013;39:233-40.

20 Shiri R, Falah-Hassani K, Lallukka T. Body mass index and the risk of disability retirement: a systematic review and meta-analysis. Occup Environ Med 2020 ;77(1):4855.

21 Åkerblom HK, Viikari J, Uhari M, et al. Atherosclerosis precursors in Finnish children and adolescents. I. General description of the cross-sectional study of 1980, and an account of the children's and families' state of health. Acta Paediatr Scand Suppl $1985 ; 318: 49-63$.

22 Lallukka T, Viikari-Juntura E, Viikari J, et al. Early work-related physical exposures and low back pain in midlife: the Cardiovascular Risk in Young Finns Study. Occup Environ Med 2017;74:163-168.

23 Halonen JI, Shiri R, Manty M, et al. Exposure to heavy physical work from early to later adulthood and primary healthcare visits due to musculoskeletal diseases in midlife: a register linked study. BMJ Open 2019;9:e031564.

24 National Institute for Health and Clinical Excellence (NICE). Obesity: the prevention, identification, assessment and management of overweight and obesity in adults and children. www.nice.org.uk/guidance/CG43. London: NICE, 2006.

25 Obesity: Identification, Assessment and Management of Overweight and Obesity in Children, Young People and Adults: Partial Update of CG43, London 2014.

26 Telama R, Yang X, Viikari J, Välimäki I, Wanne O, Raitakari O. Physical activity from childhood to adulthood: a 21-year tracking study. Am J Prev Med 2005;28:267-73. 
27 Lallukka T, Viikari-Juntura E, Raitakari OT, et al. Childhood and adult socio-economic position and social mobility as determinants of low back pain outcomes. Eur J Pain 2014;18:128-38.

28 Hanley JA, Negassa A, Edwardes MD, Forrester JE. Statistical analysis of correlated data using generalized estimating equations: an orientation. Am J Epidemiol $2003 ; 157: 364-75$.

29 Nakamura K, Shimai S, Kikuchi S, et al. Increases in body mass index and waist circumference as outcomes of working overtime. Occup Med (Lond) 1998;48:169-73.

30 Solovieva S, Lallukka T, Virtanen M, Viikari-Juntura E. Psychosocial factors at work, long work hours, and obesity: a systematic review. Scand J Work Environ Health 2013;39:241-58.

31 Virtanen M, Jokela M, Lallukka T, et al. Long working hours and change in body weight: analysis of individual-participant data from 19 cohort studies. Int J Obes (Lond) 2019; 44(6):1368-1375.

32 Lallukka T, Sarlio-Lahteenkorva S, Kaila-Kangas L, Pitkaniemi J, Luukkonen R, LeinoArjas P. Working conditions and weight gain: a 28-year follow-up study of industrial employees. Eur J Epidemiol 2008;23:303-10.

33 Bell AC, Ge K, Popkin BM. Weight gain and its predictors in Chinese adults. Int J Obes Relat Metab Disord 2001;25:1079-86.

34 Roos E, Sarlio-Lahteenkorva S, Lallukka T. Having lunch at a staff canteen is associated with recommended food habits. Public Health Nutr 2004;7:53-61.

35 Laaksonen M, Rahkonen O, Prattala R. Smoking status and relative weight by educational level in Finland, 1978-1995. Prev Med 1998;27:431-7.

36 Moreno-Maldonado C, Ramos P, Moreno C, Rivera F. How family socioeconomic status, peer behaviors, and school-based intervention on healthy habits influence adolescent eating behaviors. School Psychology International 2018;39:92-118. 
37 Albertsen K, Borg V, Oldenburg B. A systematic review of the impact of work environment on smoking cessation, relapse and amount smoked. Prev Med 2006;43:291305.

38 Albertsen K, Hannerz H, Borg V, Burr H. Work environment and smoking cessation over a five-year period. Scand J Public Health 2004;32:164-71.

39 Ayyagari P, Sindelar JL. The Impact of Job Stress on Smoking and Quitting: Evidence from the HRS. B E J Econom Anal Policy 2010;10(1):art27.

40 Lee JO, Hill KG, Hartigan LA, et al. Unemployment and substance use problems among young adults: Does childhood low socioeconomic status exacerbate the effect? Soc Sci Med 2015;143:36-44. 
Table 1: Baseline (1986/1989) characteristics of the study population. The results present proportions $(\%)$

\begin{tabular}{|c|c|}
\hline Characteristic & $\%$ \\
\hline \multicolumn{2}{|l|}{ Age in 1989} \\
\hline 18 & 25.0 \\
\hline 21 & 27.3 \\
\hline 24 & 25.3 \\
\hline 27 & 22.4 \\
\hline Female & 54.4 \\
\hline \multicolumn{2}{|l|}{ Body mass index } \\
\hline Overweight & 10.9 \\
\hline Obese & 1.9 \\
\hline \multicolumn{2}{|l|}{ Smoking } \\
\hline Past & 24.8 \\
\hline Occasional & 12.4 \\
\hline Current & 24.1 \\
\hline $\begin{array}{l}\text { Moderate or vigorous leisure-time } \\
\text { physical activity }\end{array}$ & 20.8 \\
\hline \multicolumn{2}{|l|}{ Physicality of work } \\
\hline Sedentary work & 56.7 \\
\hline $\begin{array}{l}\text { Light standing or light } \\
\text { to moderate mobile work }\end{array}$ & 27.8 \\
\hline Heavy manual work & 15.5 \\
\hline $\begin{array}{l}\text { Entering first employment between } \\
1978 \text { and } 1989\end{array}$ & 58.0 \\
\hline \multicolumn{2}{|l|}{$\begin{array}{l}\text { Age distribution of those who } \\
\text { entered their first employment }\end{array}$} \\
\hline$\leq 18$ & 33.9 \\
\hline $19-21$ & 39.9 \\
\hline $22-24$ & 20.7 \\
\hline $25-27$ & 5.5 \\
\hline
\end{tabular}


Table 2: The effects of physicality of work and entering first employment between 1978 and 1989 on the risk of overweight or obesity $\left(\mathrm{BMI} \geq 30 \mathrm{~kg} / \mathrm{m}^{2}\right.$ ), daily smoking and the rate of moderate or vigorous leisure-time physical activity in adulthood

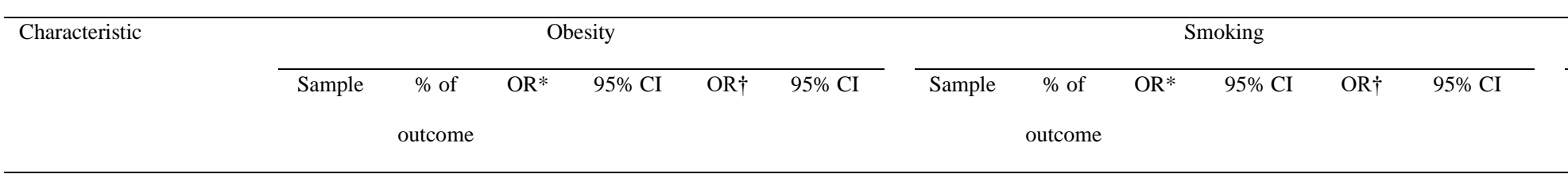

Physicality of work

\begin{tabular}{|c|c|c|c|c|c|c|c|c|c|c|c|c|}
\hline Sedentary work & 3122 & 12.1 & 1 & & 1 & & 3151 & 13.1 & 1 & & 1 & \\
\hline Light standing or light & 1494 & 16.3 & 1.44 & $1.11-1.87$ & 1.32 & $1.01-1.74$ & 1521 & 27.0 & 2.26 & $1.79-2.87$ & 1.79 & $1.39-2.30$ \\
\hline \multicolumn{13}{|c|}{ to moderate mobile work } \\
\hline Heavy manual work & 814 & 16.5 & 1.57 & $1.12-2.21$ & 1.44 & $0.99-2.08$ & 822 & 31.6 & 2.82 & $2.10-3.79$ & 2.01 & $1.47-2.76$ \\
\hline
\end{tabular}

Entering first employment

between 1978 and $1989 \pm$

\begin{tabular}{|c|c|c|c|c|c|c|c|c|c|c|c|c|}
\hline No & 2259 & 12.4 & 1 & & 1 & & 2285 & 14.5 & 1 & & 1 & \\
\hline Yes & 3210 & 15.1 & 1.24 & $0.93-1.65$ & 1.03 & $0.77-1.38$ & 3248 & 23.3 & 1.66 & $1.30-2.13$ & 1.13 & $0.87-1.46$ \\
\hline
\end{tabular}

\footnotetext{
* Model I: Adjustment for age, gender, parents' education, parents' occupation, household income, body mass index (for smoking and physical activity), smoking (for overweight/obesity and physical activity), and leisure-time physical activity (for overweight/obesity and smoking)

$\dagger$ Model II: Model I + further adjustment for participants' education, participants' occupational class, physicality of work (for entering first employment), and entering first employment (for physicality of work)

\pm Participants aged between 15 and 27 years in 1978-1989
} 
Table 3: The effect of entering first employment between 1978 and 1989 in different age groups on the risk of obesity $\left(\mathrm{BMI} \geq 30 \mathrm{~kg} / \mathrm{m}^{2}\right)$, daily smoking and the rate of moderate or vigorous leisure-time physical activity in adulthood

\begin{tabular}{|c|c|c|c|c|c|c|c|c|c|c|c|c|c|}
\hline \multirow[t]{2}{*}{ Age \pm} & \multirow{2}{*}{$\begin{array}{l}\text { Entering first } \\
\text { employment }\end{array}$} & \multicolumn{6}{|c|}{ Obesity } & \multicolumn{6}{|c|}{ Smoking } \\
\hline & & Sample & $\begin{array}{l}\% \text { of } \\
\text { outcome }\end{array}$ & OR* & $95 \% \mathrm{CI}$ & $\mathrm{OR}_{\dagger}$ & $95 \% \mathrm{CI}$ & Sample & $\%$ of & $\mathrm{OR}^{*}$ & $95 \%$ CI & $\mathrm{OR} \dagger$ & $95 \% \mathrm{CI}$ \\
\hline 18 & No & 1070 & 10.5 & 0.80 & $0.52-1.23$ & 0.88 & $0.57-1.36$ & 1085 & 13.7 & 0.97 & $0.64-1.49$ & 1.16 & $0.75-1.80$ \\
\hline$\leq 18$ & Yes & 1049 & 17.6 & 1.72 & $1.16-2.57$ & 1.60 & $1.06-2.41$ & 1072 & 35.3 & 3.28 & $2.19-4.90$ & 2.36 & $1.55-3.58$ \\
\hline 21 & No & 666 & 14.3 & 1.29 & $0.82-2.03$ & 1.48 & $0.94-2.35$ & 667 & 14.8 & 1.18 & $0.74-1.89$ & 1.51 & $0.93-2.46$ \\
\hline $19-21$ & Yes & 1251 & 15.5 & 1.42 & $0.96-2.11$ & 1.36 & $0.91-2.02$ & 1262 & 20.6 & 1.71 & $1.14-2.55$ & 1.50 & $0.99-2.25$ \\
\hline 24 & No & 310 & 9.7 & 0.70 & $0.36-1.37$ & 0.82 & $0.42-1.61$ & 318 & 12.3 & 1.07 & $0.60-1.90$ & 1.33 & $0.74-2.39$ \\
\hline $22-24$ & Yes & 737 & 11.8 & 1 & & 1 & & 738 & 12.6 & 1 & & 1 & \\
\hline 27 & No & 213 & 20.2 & 2.06 & $1.09-3.90$ & 2.13 & $1.12-4.06$ & 215 & 20.5 & 2.28 & $1.25-4.16$ & 2.08 & $1.11-3.92$ \\
\hline $25-27$ & Yes & 173 & 10.4 & 0.86 & $0.39-1.90$ & 0.93 & $0.42-2.08$ & 176 & 13.6 & 1.34 & $0.68-2.66$ & 1.57 & $0.79-3.15$ \\
\hline
\end{tabular}

\footnotetext{
* Model I: Adjustment for gender, parents' education, parents' occupation, household income, body mass index (for smoking and physical activity), smoking (for overweight/obesity and physical activity), and leisure-time physical activity (for overweight/obesity and smoking) † Model II: Model I + further adjustment for participants' education, participants' occupational class, and physicality of work \pm Participants aged 22-24 who entered labour market were used as a reference group. Participants aged 18 years who did not enter employment were those who turned 18 in 1989
}

\section{Work participation and physicality of work in young adulthood and the} development of unhealthy lifestyle habits and obesity later in life: A prospective cohort study

Rahman Shiri ${ }^{1}$, Jaana I. Halonen ${ }^{2}$, Anna Serlachius ${ }^{3}$, Nina Hutri-Kähönen ${ }^{4}$, Olli Raitakari ${ }^{5,6,7}$, Jussi Vahtera $^{7,8}$, Jorma Viikari ${ }^{9,10}$, Tea Lallukka ${ }^{1,11}$ 
${ }^{1}$ Finnish Institute of Occupational Health, Helsinki, Finland

${ }^{2}$ National Institute for Health and Welfare, Helsinki, Finland

${ }^{3}$ Department of Psychological Medicine, Faculty of Medical and Health Sciences, University of Auckland, Auckland, New Zealand

${ }^{4}$ Department of Paediatrics, Faculty of Medicine and Health Technology, Tampere University and Tampere University Hospital, Tampere, Finland

${ }^{5}$ Research Centre of Applied and Preventive Cardiovascular Medicine, University of Turku, Turku, Finland

${ }^{6}$ Department of Clinical Physiology and Nuclear Medicine, Turku University Hospital, Turku, Finland

${ }^{7}$ Centre for Population Health Research, University of Turku and Turku University Hospital, Turku, Finland

${ }^{8}$ Department of Public Health, University of Turku, Turku, Finland

${ }^{9}$ Department of Medicine, University of Turku, Turku, Finland

${ }^{10}$ Division of Medicine, Turku University Hospital, Turku, Finland

${ }^{11}$ Department of Public Health, University of Helsinki, Helsinki, Finland 


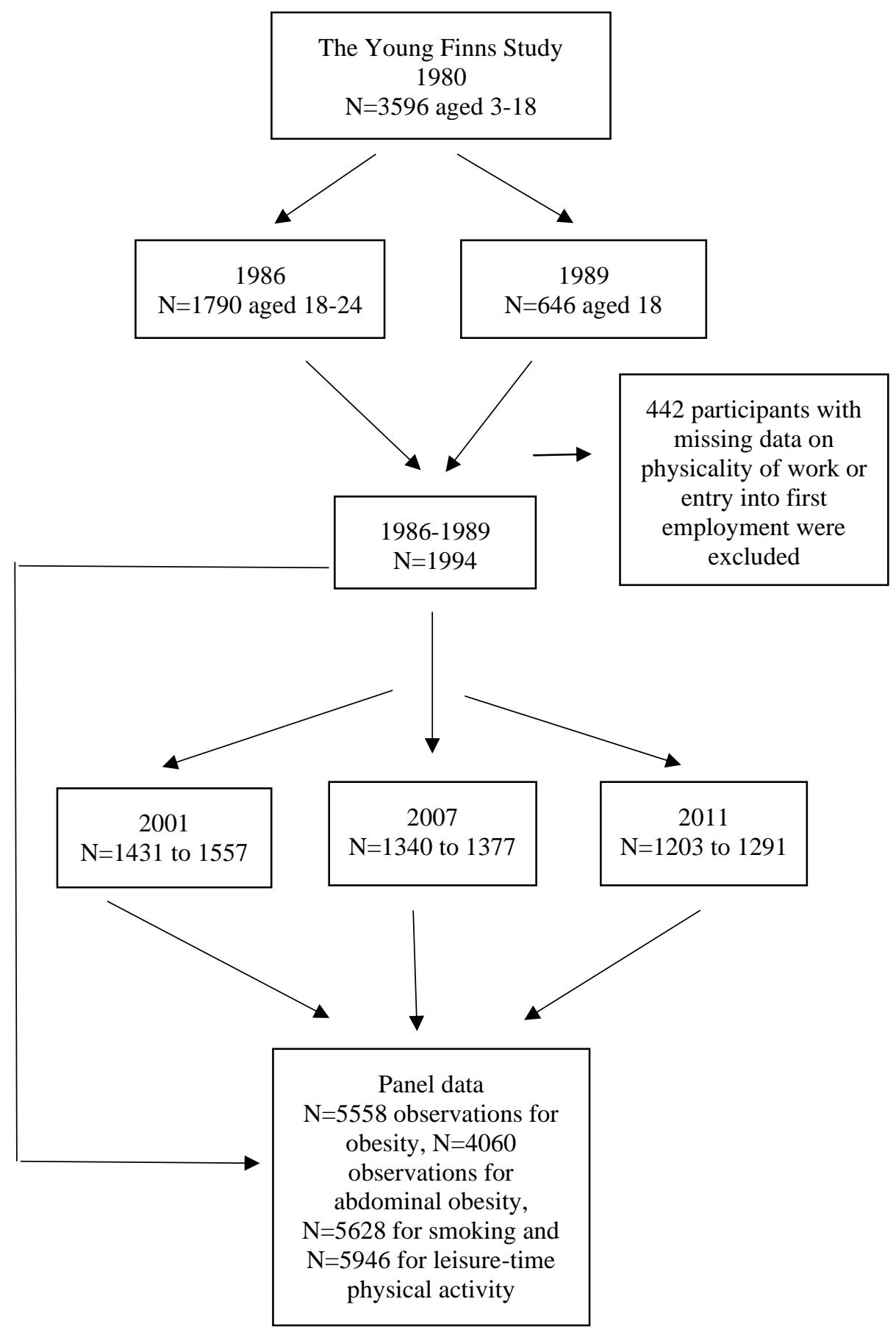

Figure S1: Flow chart of the study population, the Young Finns Study 
Table S1: The effects of physicality of work and entry into first employment between 1978 and 1989 on the risk of obesity (BMI $\geq 30 \mathrm{~kg} / \mathrm{m}^{2}$ ) in men and women

\begin{tabular}{|c|c|c|c|c|c|c|c|c|}
\hline \multirow[t]{2}{*}{ Characteristic } & \multicolumn{4}{|c|}{ Men } & \multicolumn{4}{|c|}{ Women } \\
\hline & Sample & $\begin{array}{c}\% \text { of } \\
\text { outcome }\end{array}$ & $\mathrm{OR}^{*}$ & $95 \% \mathrm{CI}$ & Sample & $\begin{array}{c}\% \text { of } \\
\text { outcome }\end{array}$ & $\mathrm{OR}^{*}$ & $95 \% \mathrm{CI}$ \\
\hline \multicolumn{9}{|l|}{ Physicality of work } \\
\hline Sedentary work & 1123 & 12.2 & 1 & & 1999 & 12.0 & 1 & \\
\hline $\begin{array}{l}\text { Light standing or light } \\
\text { to moderate mobile work }\end{array}$ & 603 & 16.3 & 1.26 & $0.80-1.99$ & 891 & 16.3 & 1.38 & $0.96-1.98$ \\
\hline Heavy manual work & 644 & 15.8 & 1.22 & $0.77-1.92$ & 170 & 18.8 & 2.03 & $1.07-3.84$ \\
\hline \multicolumn{9}{|l|}{ Entry into first employment } \\
\hline No & 1063 & 12.5 & 1 & & 1196 & 12.3 & 1 & \\
\hline Yes & 1334 & 15.9 & 1.03 & $0.67-1.57$ & 1876 & 14.5 & 1.07 & $0.71-1.62$ \\
\hline
\end{tabular}

*Adjustment for age, parents' education, parents' occupation, household income, participants' education, participants' occupational class, physicality of work, entry into first employment, smoking, and leisure-time physical activity 
Table S2: The effect of entry into first employment between 1978 and 1989 in different age groups on the risk of obesity $\left(\mathrm{BMI} \geq 30 \mathrm{~kg} / \mathrm{m}^{2}\right)$ in men and women

\begin{tabular}{|c|c|c|c|c|c|c|c|c|c|}
\hline \multirow[t]{2}{*}{ Age } & \multirow{2}{*}{$\begin{array}{l}\text { Entry into } \\
\text { first } \\
\text { employment }\end{array}$} & \multicolumn{4}{|c|}{ Men } & \multicolumn{4}{|c|}{ Women } \\
\hline & & Sample & $\begin{array}{c}\% \text { of } \\
\text { outcome }\end{array}$ & OR* & $95 \% \mathrm{CI}$ & Sample & $\begin{array}{c}\% \text { of } \\
\text { outcome }\end{array}$ & $\mathrm{OR}^{*}$ & $95 \% \mathrm{CI}$ \\
\hline 18 & No & 492 & 10.4 & 0.80 & $0.39-1.62$ & 578 & 10.6 & 0.93 & $0.53-1.65$ \\
\hline$\leq 18$ & Yes & 530 & 16.0 & 1.28 & $0.64-2.57$ & 519 & 19.3 & 1.90 & $1.13-3.20$ \\
\hline$\overline{2} 1$ & No & 302 & 14.2 & 1.25 & $0.57-2.73$ & 364 & 14.3 & 1.71 & $0.96-3.03$ \\
\hline $19-21$ & Yes & 490 & 16.9 & 1.36 & $0.70-2.66$ & 761 & 14.6 & 1.35 & $0.81-2.24$ \\
\hline 24 & No & 145 & 7.6 & 0.63 & $0.22-1.83$ & 165 & 11.5 & 1.05 & $0.42-2.61$ \\
\hline $22-24$ & Yes & 234 & 12.4 & 1 & & 503 & 11.5 & 1 & \\
\hline 27 & No & 124 & 22.6 & 2.10 & $0.85-5.16$ & 89 & 16.9 & 1.90 & $0.65-5.54$ \\
\hline $25-27$ & Yes & 80 & 18.8 & 2.09 & $0.73-5.97$ & 93 & 3.2 & 0.17 & $0.02-1.25$ \\
\hline
\end{tabular}

*Adjustment for parents' education, parents' occupation, household income, participants' education, participants' occupational class, physicality of work, smoking and leisure-time physical activity 
Table S3: The effects of physicality of work and entry into first employment between 1978 and 1989 on the risk of abdominal obesity

\begin{tabular}{|c|c|c|c|c|c|c|}
\hline Characteristic & Sample & $\begin{array}{c}\% \text { of } \\
\text { outcome }\end{array}$ & $\mathrm{OR}^{*}$ & $95 \% \mathrm{CI}$ & $\mathrm{OR} \dagger$ & $95 \% \mathrm{CI}$ \\
\hline \multicolumn{7}{|l|}{ Workload } \\
\hline Sedentary work & 2249 & 26.8 & 1 & & 1 & \\
\hline $\begin{array}{l}\text { Light standing or light } \\
\text { to moderate mobile work }\end{array}$ & 1097 & 32.8 & 1.30 & $1.04-1.63$ & 1.20 & $0.95-1.51$ \\
\hline Heavy manual work & 592 & 29.7 & 1.48 & $1.10-1.99$ & 1.32 & $0.96-1.82$ \\
\hline \multicolumn{7}{|l|}{$\begin{array}{l}\text { Entry into first } \\
\text { employment }\end{array}$} \\
\hline No & 1598 & 25.8 & 1 & & 1 & \\
\hline Yes & 2394 & 31.0 & 1.16 & $0.92-1.45$ & 0.99 & $0.78-1.26$ \\
\hline
\end{tabular}

* Model I: Adjustment for age, gender, parents' education, parents' occupation, household income, smoking and leisure-time physical activity

$\uparrow$ Model II: Model I + further adjustment for participants' education, participants' occupational class, physicality of work (for entry into first employment), and entry into first employment (for physicality of work) 
Table S4: The effect of entry into first employment between 1978 and 1989 in different age groups on the risk of abdominal obesity

\begin{tabular}{llllllll}
\hline Age & $\begin{array}{l}\text { Entry into } \\
\text { first } \\
\text { employment }\end{array}$ & Sample & $\begin{array}{l}\% \text { of } \\
\text { outcome }\end{array}$ & OR* & 95\% CI & OR $\dagger$ & $95 \%$ CI \\
\hline & No & 746 & 23.1 & 0.91 & $0.64-1.31$ & 0.98 & $0.68-1.42$ \\
18 & Yes & 775 & 33.3 & 1.43 & $1.01-2.01$ & 1.28 & $0.89-1.82$ \\
$\leq 18$ & No & 459 & 29.2 & 1.26 & $0.85-1.86$ & 1.41 & $0.94-2.10$ \\
21 & Yes & 934 & 32.2 & 1.32 & $0.95-1.84$ & 1.26 & $0.91-1.76$ \\
$19-21$ & No & 233 & 22.3 & 0.72 & $0.44-1.18$ & 0.81 & $0.49-1.35$ \\
24 & Yes & 553 & 27.1 & 1 & & 1 & \\
$22-24$ & No & 160 & 33.8 & 1.62 & $0.94-2.80$ & 1.61 & $0.92-2.79$ \\
27 & 132 & 25.0 & 1.08 & $0.59-1.97$ & 1.16 & $0.64-2.12$ \\
$25-27$ & Yes & 132 & & & & & \\
\hline
\end{tabular}

* Model I: Adjustment for age, gender, parents' education, parents' occupation, household income, smoking and leisure-time physical activity

$\dagger$ Model II: Model I + further adjustment for participants' education, participants' occupational class, and physicality of work 
Table S5: The effects of physicality of work and entry into first employment between 1978 and 1989 on the risk of smoking in men and women

\begin{tabular}{|c|c|c|c|c|c|c|c|c|}
\hline \multirow[t]{2}{*}{ Characteristic } & \multicolumn{4}{|c|}{ Men } & \multicolumn{4}{|c|}{ Women } \\
\hline & Sample & $\begin{array}{l}\% \text { of } \\
\text { outcome }\end{array}$ & OR* & $95 \%$ CI & Sample & $\begin{array}{l}\% \text { of } \\
\text { outcome }\end{array}$ & $\mathrm{OR}^{*}$ & $95 \% \mathrm{CI}$ \\
\hline \multicolumn{9}{|l|}{ Physicality of work } \\
\hline Sedentary work & 1121 & 14.8 & 1 & & 2030 & 12.2 & 1 & \\
\hline $\begin{array}{l}\text { Light standing or light } \\
\text { to moderate mobile work }\end{array}$ & 608 & 32.2 & 1.92 & $1.31-2.81$ & 913 & 23.6 & 1.72 & $1.21-2.43$ \\
\hline Heavy manual work & 647 & 32.0 & 1.84 & $1.24-2.73$ & 175 & 30.3 & 2.81 & $1.60-4.91$ \\
\hline \multicolumn{9}{|l|}{ Entry into first employment } \\
\hline No & 1063 & 17.8 & 1 & & 1222 & 11.6 & 1 & \\
\hline Yes & 1338 & 28.9 & 1.18 & $0.83-1.68$ & 1910 & 19.3 & 1.04 & $0.71-1.53$ \\
\hline
\end{tabular}

*Adjustment for age, parents' education, parents' occupation, household income, participants' education, participants' occupational class, body mass index, leisure-time physical activity, physicality of work (for entry into first employment), and entry into first employment (for physicality of work) 
Table S6: The effect of entry into first employment between 1978 and 1989 in different age groups on the risk of smoking in men and women

\begin{tabular}{|c|c|c|c|c|c|c|c|c|c|}
\hline \multirow[t]{2}{*}{ Age } & \multirow{2}{*}{$\begin{array}{l}\text { Entry into } \\
\text { first } \\
\text { employment }\end{array}$} & \multicolumn{4}{|c|}{ Men } & \multicolumn{4}{|c|}{ Women } \\
\hline & & Sample & $\begin{array}{c}\% \text { of } \\
\text { outcome }\end{array}$ & OR* & $95 \%$ CI & Sample & $\begin{array}{c}\% \text { of } \\
\text { outcome }\end{array}$ & OR* & $95 \% \mathrm{CI}$ \\
\hline 18 & No & 491 & 16.7 & 1.11 & $0.57-2.16$ & 594 & 11.3 & 1.25 & $0.69-2.25$ \\
\hline$\leq 18$ & Yes & 534 & 40.8 & 2.36 & $1.25-4.45$ & 538 & 29.7 & 2.33 & $1.32-4.10$ \\
\hline 21 & No & 299 & 18.1 & 1.47 & $0.70-3.11$ & 368 & 12.2 & 1.56 & $0.81-3.01$ \\
\hline $19-21$ & Yes & 490 & 24.1 & 1.37 & $0.72-2.60$ & 772 & 18.4 & 1.60 & $0.93-2.73$ \\
\hline 24 & No & 146 & 17.8 & 1.38 & $0.58-3.30$ & 172 & 7.6 & 1.21 & $0.54-2.71$ \\
\hline $22-24$ & Yes & 232 & 16.4 & 1 & & 506 & 10.9 & 1 & \\
\hline 27 & No & 127 & 21.3 & 1.72 & $0.72-4.15$ & 88 & 19.3 & 2.78 & $1.09-7.08$ \\
\hline $25-27$ & Yes & 82 & 14.6 & 1.61 & $0.55-4.68$ & 94 & 12.8 & 1.54 & $0.61-3.87$ \\
\hline
\end{tabular}

*Adjustment for parents' education, parents' occupation, household income, participants' education, participants' occupational class, physicality of work, body mass index, and leisure-time physical activity 
Table S7: The effects of physicality of work and entry into first employment between 1978 and 1989 on the rate of moderate or vigorous leisure-time physical activity in men and women

\begin{tabular}{|c|c|c|c|c|c|c|c|c|}
\hline \multirow[t]{2}{*}{ Characteristic } & \multicolumn{4}{|c|}{ Men } & \multicolumn{4}{|c|}{ Women } \\
\hline & Sample & $\begin{array}{c}\text { \% of } \\
\text { outcome }\end{array}$ & $\mathrm{OR}^{*}$ & $95 \% \mathrm{CI}$ & Sample & $\begin{array}{c}\% \text { of } \\
\text { outcome }\end{array}$ & $\mathrm{OR}^{*}$ & $95 \%$ CI \\
\hline \multicolumn{9}{|l|}{ Physicality of work } \\
\hline Sedentary work & 1193 & 36.0 & 1 & & 2135 & 30.9 & 1 & \\
\hline $\begin{array}{l}\text { Light standing or light } \\
\text { to moderate mobile work }\end{array}$ & 656 & 28.2 & 0.95 & $0.70-1.30$ & 969 & 25.7 & 0.99 & $0.78-1.26$ \\
\hline Heavy manual work & 672 & 26.3 & 1.06 & $0.75-1.48$ & 188 & 23.9 & 1.02 & $0.64-1.63$ \\
\hline \multicolumn{9}{|l|}{ Entry into first employment } \\
\hline No & 1115 & 35.7 & 1 & & 1270 & 32.4 & 1 & \\
\hline Yes & 1428 & 27.7 & 0.86 & $0.64-1.15$ & 2022 & 26.7 & 0.88 & $0.70-1.12$ \\
\hline
\end{tabular}

*Adjustment for age, parents' education, parents' occupation, household income, participants' education, participants' occupational class, physicality of work, entry into first employment, body mass index, and smoking 
Table S8: The effect of entry into first employment between 1978 and 1989 in different age groups on the rate of moderate or vigorous leisure-time physical activity in men and women

\begin{tabular}{|c|c|c|c|c|c|c|c|c|c|}
\hline \multirow[t]{2}{*}{ Age } & \multirow{2}{*}{$\begin{array}{l}\text { Entry into } \\
\text { first } \\
\text { employment }\end{array}$} & \multicolumn{4}{|c|}{ Men } & \multicolumn{4}{|c|}{ Women } \\
\hline & & Sample & $\begin{array}{c}\% \text { of } \\
\text { outcome }\end{array}$ & $\mathrm{OR}^{*}$ & $95 \% \mathrm{CI}$ & Sample & $\begin{array}{c}\% \text { of } \\
\text { outcome }\end{array}$ & $\mathrm{OR}^{*}$ & $95 \%$ CI \\
\hline 18 & No & 519 & 38.0 & 1.02 & $0.65-1.59$ & 614 & 32.9 & 0.90 & $0.66-1.23$ \\
\hline$\leq 18$ & Yes & 558 & 23.1 & 0.68 & $0.42-1.10$ & 566 & 22.6 & 0.76 & $0.53-1.07$ \\
\hline$\overline{2} 1$ & No & 301 & 35.9 & 0.97 & $0.58-1.60$ & 382 & 34.0 & 0.99 & $0.68-1.44$ \\
\hline $19-21$ & Yes & 531 & 27.7 & 0.73 & $0.46-1.14$ & 818 & 24.3 & 0.75 & $0.55-1.01$ \\
\hline 24 & No & 157 & 33.1 & 0.85 & $0.46-1.56$ & 186 & 30.1 & 0.85 & $0.55-1.31$ \\
\hline $22-24$ & Yes & 251 & 35.5 & 1 & & 535 & 32.9 & 1 & \\
\hline 27 & No & 138 & 29.7 & 0.78 & $0.41-1.50$ & 88 & 27.3 & 0.85 & $0.44-1.62$ \\
\hline $25-27$ & Yes & 88 & 35.2 & 0.88 & $0.42-1.86$ & 103 & 35.9 & 1.08 & $0.62-1.88$ \\
\hline
\end{tabular}

*Adjusted for parents' education, parents' occupation, household income, participants' education, participants' occupational class, physicality of work, body mass index, and smoking 